\title{
Asymmetry of Daily Temperature Records
}

\section{Citation}

Ashkenazy, Yosef, Yizhak Feliks, Hezi Gildor, and Eli Tziperman. 2008. "Asymmetry of Daily Temperature Records." Journal of the Atmospheric Sciences 65 (10) (October): 3327-3336. doi:10.1175/2008jas2662.1. http://dx.doi.org/10.1175/2008JAS2662.1.

\section{Published Version}

doi:10.1175/2008jas2662.1

\section{Permanent link}

http://nrs.harvard.edu/urn-3:HUL.InstRepos:11893408

\section{Terms of Use}

This article was downloaded from Harvard University's DASH repository, and is made available under the terms and conditions applicable to Other Posted Material, as set forth at http:// nrs.harvard.edu/urn-3:HUL.InstRepos:dash.current.terms-of-use\#LAA

\section{Share Your Story}

The Harvard community has made this article openly available.

Please share how this access benefits you. Submit a story.

Accessibility 


\title{
Asymmetry of Daily Temperature Records
}

\author{
YOSEF ASHKENAZY \\ Solar Energy and Environmental Physics, BIDR, Ben-Gurion University, Midreshet Ben-Gurion, Israel \\ YIZHAK FELIKS \\ Department of Mathematics, Israel Institute for Biological Research, Ness-Ziona, Israel \\ Hezi GILDOR \\ Environmental Sciences, Weizmann Institute, Rehovot, Israel
}

ELI TZIPERMAN

Department of Earth and Planetary Sciences, and Division of Engineering and Applied Sciences, Harvard University, Cambridge, Massachusetts

(Manuscript received 30 October 2007, in final form 23 March 2008)

\begin{abstract}
The authors study the NCEP-NCAR reanalysis temperature records and find that surface daily mean temperature cools rapidly and warms gradually at the midlatitudes (around $40^{\circ} \mathrm{N}$ and $40^{\circ} \mathrm{S}$ ). This "asymmetry" is partially related to the midlatitude cyclone activity, in which cold fronts are significantly faster and steeper than warm fronts, and to intrusions of cold air. The gradual warming may be attributed also to the radiative relaxation to average atmospheric conditions after the passage of cold fronts or other intrusions of cold air. At the high latitudes there is an opposite asymmetry with rapid warming and gradual cooling; this asymmetry may be attributed to the radiative relaxation to average cold atmospheric conditions after the passage of warm fronts or intrusions of warm air.
\end{abstract}

\section{Introduction}

Among the various measures that quantify past and future climate, temperature is one of the most common and important measures. One of the basic characteristics of earth climate in the past 3 million years or so is the asymmetry of the glacial-interglacial cycles in which temperature cools gradually and warms rapidly (Imbrie et al. 1984; Lisiecki and Raymo 2005; Ashkenazy and Tziperman 2004). This asymmetry is related to the slow buildup of the Northern Hemisphere ice sheets and to their relative rapid melting. Similar asym-

Corresponding author address: Yosef Ashkenazy, Department of Solar Energy and Environmental Physics, The J. Blaustein Institutes for Desert Research, Ben-Gurion University, Sede Boker Campus, 84990 Israel.

E-mail: ashkena@bgu.ac.il metry is one of the main characteristics of the Heinrich (Heinrich 1988) and Dansgaard-Oeschger (DO) events (Dansgaard et al. 1984); the asymmetry of the DO events was attributed to changes in the thermohaline circulation (e.g., Winton 1993; Winton and Sarachik 1993; Lenderink and Haarsma 1994; Rahmstorf and Ganopolski 1999; Kaspi 2002; Kaspi et al. 2004; Vallis 2000; Wang and Mysak 2006).

Asymmetry is found in other climate records, such as in the $\sim 11-y r$ sunspot cycle (Hoyt and Schatten 1998a,b) and in seasonal river discharge, which increases rapidly and relaxes more gradually (Livina et al. 2003). Asymmetry is of interest because it may be a basic sign for a nonlinear underlying process (Schreiber and Schmitz 2000; Bartos and Jánosi 2005, 2006; Gyüre et al. 2007) and the asymmetry of different climate records may be associated with different underlying nonlinear dynamics. 
Recently it was found (Bartos and Jánosi 2005, 2006; Gyüre et al. 2007), based on the available land temperature records, that daily mean temperature cools rapidly and warms gradually. This analysis was limited to continental areas with long enough temperature records and thus does not provide global coverage. More recently, asymmetry of temperature records in rotating tank experiments has been reported and has been associated with the observed asymmetry of daily temperature records (Gyüre et al. 2007).

Here we analyze the asymmetry of temperature records of the National Centers for Environmental Prediction (NCEP)-National Center for Atmospheric Research (NCAR) (Kalnay et al. 1996) database. The main advantage of this reanalysis data is its global 3D coverage. As follows from Bartos and Jánosi (2005) and Gyüre et al. (2007), we find here that the daily temperature asymmetry is limited to the midlatitudes; we propose that the asymmetry is partially due to the fact that cold fronts, which usually occur at these latitudes, are sharper and induce faster transitions than warm fronts. The gradual warming may also be due to the gradual warming to average atmospheric conditions associated with radiative relaxation after the passage of cold fronts. At the high latitudes there is an opposite asymmetry (with rapid warming and gradual cooling), which may be linked to the gradual radiative relaxation to cold atmospheric average conditions after the passage of warm fronts and/or intrusions of warm lowlatitude air.

Although it is clear that atmospheric dynamics are nonlinear, several studies suggested that the atmospheric circulation is stable, that the synoptic-scale activities may be approximated by linear dynamics, and that their growth may be approximated as a linear transient growth of optimal perturbations (e.g., Farrell 1988; DelSol and Farrell 1995; Farrell and Ioannou 1996; Whitaker and Sardeshmukh 1998; Zhang and Held 1999). We propose that the asymmetry of temperature time series may be used as a measure of the nonlinearity, possibly adding another point of view to this discussion.

\section{Data and analysis}

For the asymmetry analysis we use $59 \mathrm{yr}$ (from 1948 to 2006) of the NCEP-NCAR reanalysis data (Kalnay et al. 1996); the database includes a global, multilevel coverage of temperature. The finer temporal resolution is 6 hourly (4 daily), whereas the focus of this paper is the daily mean temperature asymmetry. The spatial resolution is $2.5^{\circ}$.

Given a temperature record $T_{i}$, let the temperature

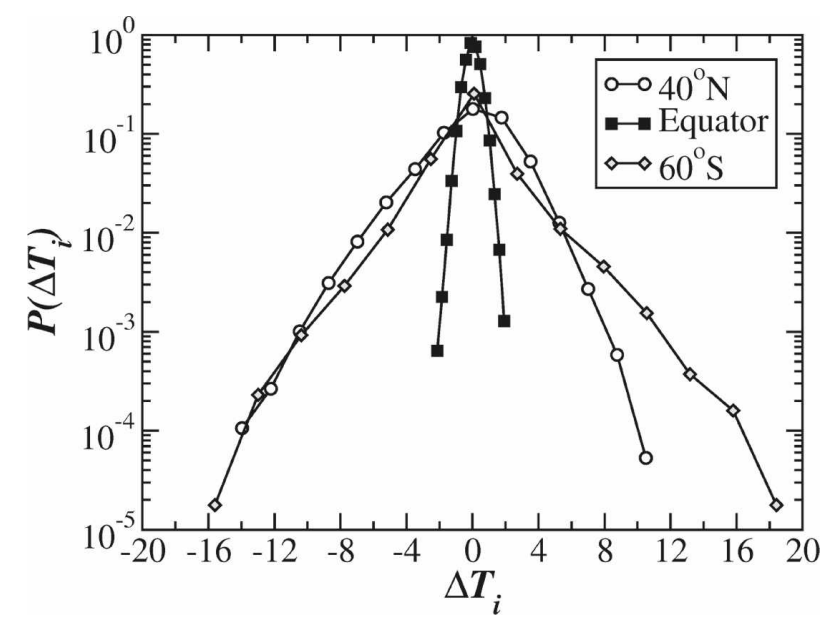

FIG. 1. The probability distribution of daily temperature records from $100^{\circ} \mathrm{E}$ at $40^{\circ} \mathrm{N}$ (circles), the equator (squares), and $60^{\circ} \mathrm{S}$ (diamonds). The asymmetry values are $A=0.55,0.5$, and 0.47 , respectively.

increment time series be $T_{i+\tau}-T_{i}$ for some specified time lag $\tau$. The temperature asymmetry is then defined as the ratio of positive temperature increments to the total (positive plus negative) steps:

$$
A(\tau)=\frac{p}{p+n}=\frac{\sum \theta\left(T_{i+\tau}-T_{i}\right)}{\sum \theta\left(T_{i+\tau}-T_{i}\right)+\sum \theta\left(T_{i}-T_{i+\tau}\right)},
$$

where $\theta(x)=1$ for $x>0$ and is zero otherwise. Equal consecutive temperatures $\left(T_{i}=T_{i+1}\right)$ are excluded from the calculation. Such cases never exceed a few percent of the data. Thus, when temperature warms rapidly and cools gradually, $A<0.5$. When $A \approx 0.5$, the record is symmetric. Below we discuss the error bars within which the signal is considered to be symmetric.

The difference between the relative number of warming and cooling events is $(p-n) /(n+p)=2 p /$ $(n+p)-1$. Thus, for an asymmetry value of $A=0.53$, for example, there are $6 \%$ more warming increments than cooling increments ( $\sim 22$ days a year when considering the daily mean temperatures).

Before presenting the asymmetry results, we show in Fig. 1 three examples for the probability distribution of the increments in daily temperature time series, $\Delta T_{i}=$ $T_{i+1 \text { day }}-T_{i}$, for $100^{\circ} \mathrm{E}$ at $40^{\circ} \mathrm{N}$, the equator, and $60^{\circ} \mathrm{S}$. For $40^{\circ} \mathrm{N}$ the distribution is stretched to the left, indicating that cooling increments are more pronounced than the warming increments; to maintain an average $\overline{\Delta T}=0$ there must be more (positive) warming steps than (negative) cooling steps and hence the asymmetry should be $A>0.5$. At the equator, the probability distribution is almost symmetric, with $A \approx 0.5$. At $60^{\circ} \mathrm{S}$ the 


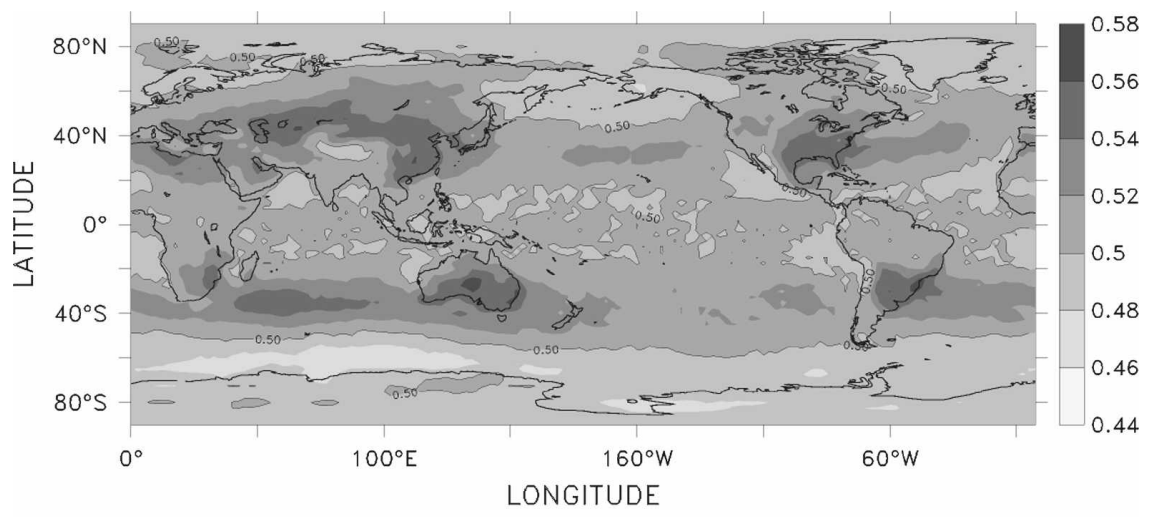

ASYMMETRY $\mathrm{p} /(\mathrm{n}+\mathrm{p})$

FIG. 2. A map of the asymmetry measure $A(\tau=1$ day), based on the surface daily mean temperature of the NCEP-NCAR reanalysis. The average values for the time period 19482006 are shown. The standard deviation of the phase randomized data and shuffled data is less than 0.002 , indicating that the asymmetry patterns are highly significant statistically. The 0.5 contour line is also included.

probability distribution is stretched to the right, indicating an opposite asymmetry with $A<0.5$. The asymmetries for these three cases are $A=0.55,0.5$, and 0.47 , respectively.

We note that because temperature records, to a very good approximation, do not exhibit an overall trend on a daily basis, the asymmetry $A$ should be highly correlated with the ratio between the average temperature increment and the sum of average daily temperature increments and decrements, as was verified by Bartos and Jánosi (2005). The seasonal cycle may lead to seasonal variation of $A$. However, when considering the annual average of the asymmetry measure (1), this seasonal effect disappears. Nonetheless, to exclude the seasonality effect when considering the asymmetry within the annual cycle, we first filter out the seasonal cycle from the daily temperature records.

\section{Results: Daily mean temperature asymmetry}

In Fig. 2 we show the spatial distribution of the asymmetry measure $A$ ( $\tau=1$ day) of the daily surface temperature records. There are several features that are worth noting. (i) The asymmetry is maximal at the midlatitudes $\left(\sim 40^{\circ} \mathrm{N}\right.$ and $\left.\sim 40^{\circ} \mathrm{S}\right)$, reflecting rapid cooling and gradual warming. (ii) At the tropics the asymmetry is $\sim 0.5$, indicating that on average the warming and cooling rates are almost the same. (iii) Asymmetry is more pronounced over land. (iv) The high-asymmetry patterns approximately overlap the storm track. (v) High asymmetry values tend to be found at eastern part of the continents. (vi) Opposite asymmetry is observed at the high latitudes, indicating rapid warming and gradual cooling. Features (i) to (iv) suggest that the observed asymmetry may be related to midlatitude cyclone/anticyclone activity.

The features of Fig. 2 described above are more easily noticed in the zonal average shown in Fig. 3a. Here the asymmetry is maximal around $40^{\circ} \mathrm{S}$ and $40^{\circ} \mathrm{N}$, whereas it is 0.5 at the tropics and less than 0.5 at the high latitudes. The asymmetry is also seen in Fig. 3a to be maximal over land.

In Fig. 3b, we show the asymmetry curves for different time lags $\tau$ of Eq. (1). The asymmetry vanishes for time scale $\tau=1$ week with asymmetry value of $\approx 0.5$ everywhere. This is another indication that the observed asymmetry of daily temperature records may be associated with synoptic-scale activity that has a time scale of approximately 1 week (Holton 1992).

If indeed the observed asymmetry is related to midlatitude cyclone activity and more specifically to the related progression of cold/warm fronts, the asymmetry should decay above the typical altitude of this activity. In Fig. 4 we show the asymmetry of daily temperature records (using a 1-day lag, $\tau=1$ day) at pressure levels of 850 (Figs. 4a,c) and $500 \mathrm{hPa}$ (Figs. 4b,d). At the 850-hPa level, the asymmetry is very similar to that of the surface level (Fig. 2 and Fig. 3a), whereas at the greater height of $500 \mathrm{hPa}$ (about $5.5 \mathrm{~km}$ ) the asymmetry of the midlatitudes is much less pronounced. The typical cold front height is about $4.5 \mathrm{~km}$ (Trewartha 1954) and "at 500-mb level well-defined frontal zones are rather unusual" (Wallace and Hobbs 2006), supporting our suggestion that the observed asymmetry should be linked to synoptic-scale, cyclonic, cold or warm front activity. 

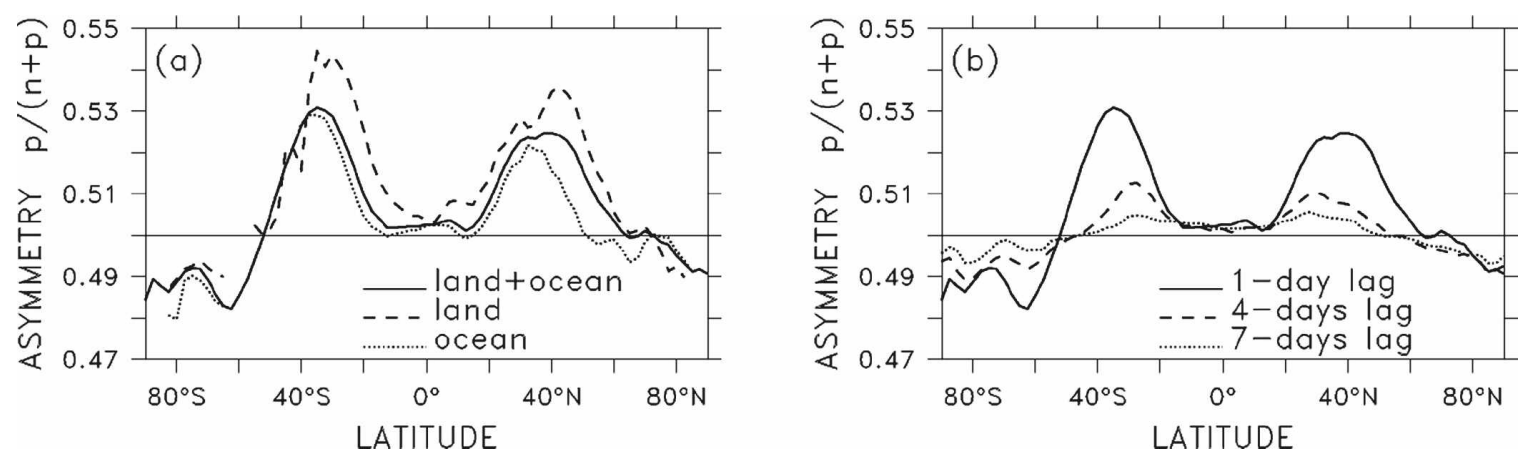

FIG. 3. (a) Zonal averages of the map shown in Fig. 2 over the entire latitude band (solid), over land (dashed), and over the ocean (dotted). (b) Zonal averages of the map shown in Fig. 2 for different time lags of $\tau=1$ day (solid), $\tau=4$ days (dashed), and $\tau=1$ week (dotted). The asymmetry vanishes for 1-week lag, suggesting that the observed asymmetry is linked to synoptic-scale activity whose time scale is a few days (see text).

Although the seasonal cycle was filtered out before calculating the asymmetry, one may wonder whether there are other seasonal effects on the asymmetry measure. The zonal and monthly average asymmetry of the surface daily temperatures using 1-day time lag $[\tau=1$ day in Eq. (1)] are presented in Fig. 5. There is a tendency of the asymmetry measure to "follow the sun," that is, the midlatitude asymmetry is shifted to higher latitudes during summer. There is also a tendency of the midlatitude asymmetry to maximize during the spring and fall.

\section{The statistical significance of the results and implications to underlying nonlinearity}

We estimate the statistical significance of the results in two ways: (i) We randomly selected time series from 100 grid points from the database and shuffled each of the time series by randomly exchanging pairs of points.
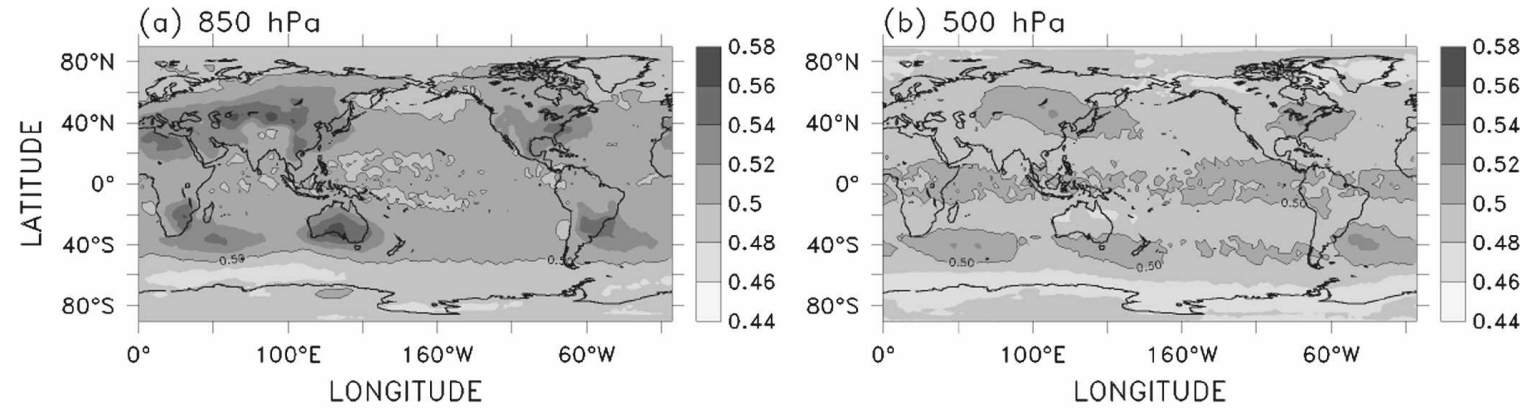

ASYMMETRY $p /(n+p)$

\section{ASYMMETRY $p /(n+p)$}
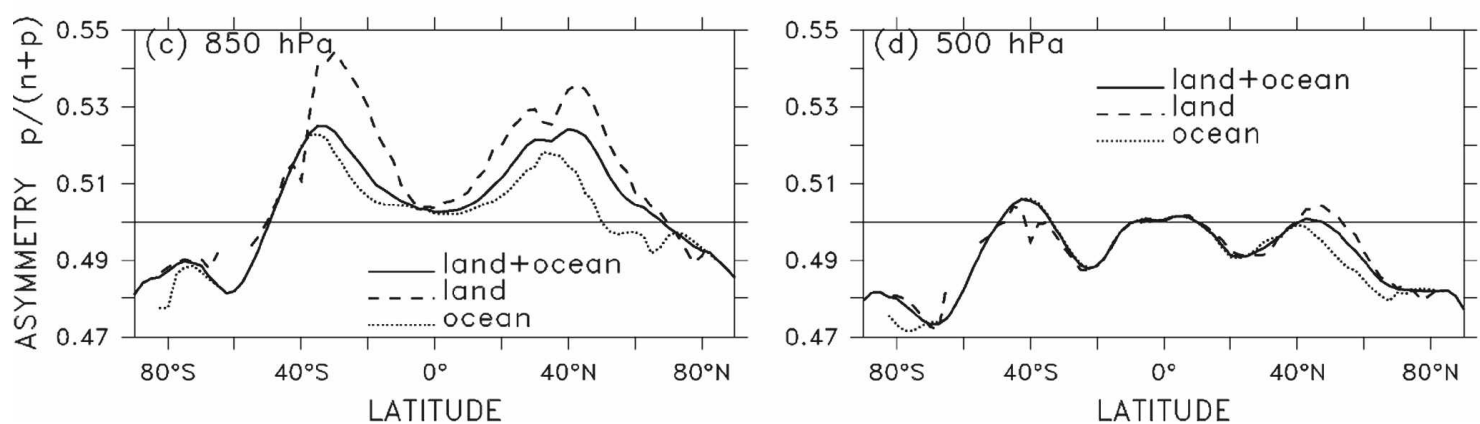

FIG. 4. As in Fig. 2, but for (a) 850- and (b) 500-hPa pressure levels; the zonal averages (as in Fig. 3a) of (a) and (b) are shown in (c) and (d). The asymmetry of 850-hPa level resembles the asymmetry of the surface level, whereas for the 500-hPa level the midlatitude asymmetry is very weak. 


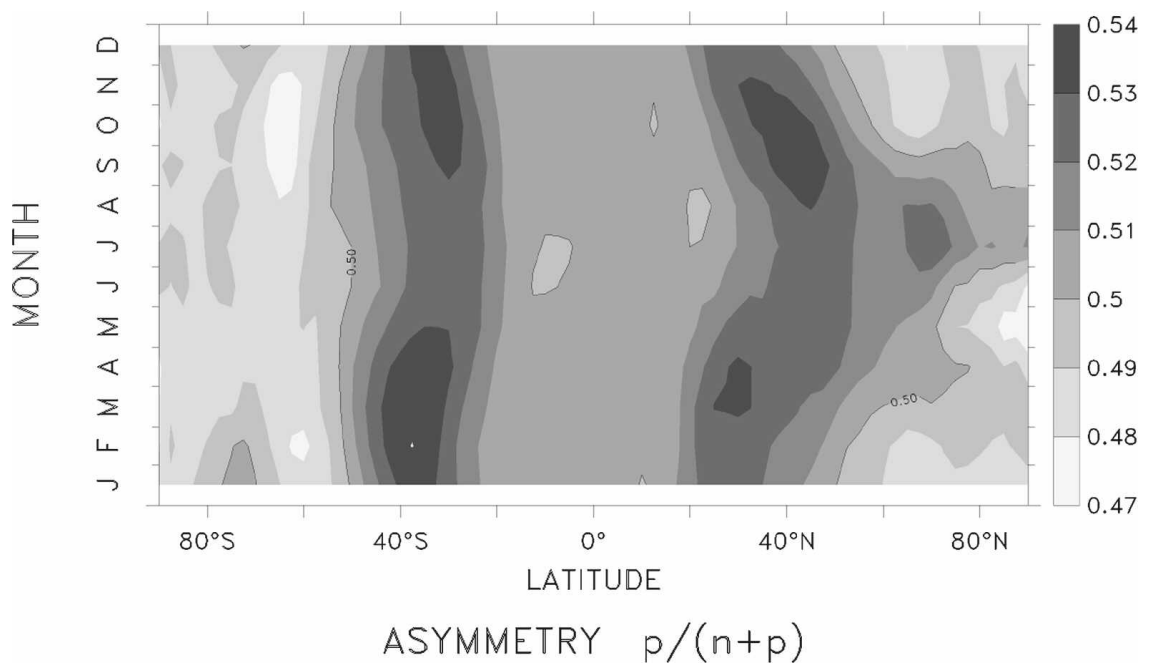

FIG. 5. The zonal average asymmetry of surface daily temperature records $A$ ( $\tau=1$ day) for different months. The 0.5 contour line is indicated by the black line.

In this way we keep the probability distribution of the original data but destroy any temporal correlations. (ii) We use the Fourier-phase randomization test for nonlinearity (Schreiber and Schmitz 1996, 2000), in which just the Fourier phases are randomized while the power spectrum and the probability distribution remain almost unchanged. In this way the asymmetry and the nonlinear properties of the time series are destroyed. We calculate the asymmetry using both methods and find, as expected, an average value of 0.5 and a standard deviation less than 0.002 , indicating that the asymmetry results reported above are highly significant. In addition, the asymmetry is an indication for the nonlinearity of the underlying processes, as was also previously reported (Bartos and Jánosi 2005, 2006). Moreover, because the asymmetry points to a "time direction" in the time series, the asymmetry cannot be reproduced using simple autoregression stochastic linear models, which are time invariant.

\section{Why daily temperature asymmetry?}

What is the mechanism behind the observed midlatitude asymmetry according to which daily temperature increases gradually and cools rapidly, and why do the high latitudes exhibit an opposite asymmetry? The results presented above indicate that the asymmetry may be related to synoptic activity that is associated with midlatitude fronts. The midlatitude low-pressure eddies are responsible for heat transport from low to high latitudes (Lindzen 1993). These low-pressure cyclones move to the east and are usually composed of cold and warm fronts that rotate cyclonically (e.g., Trewartha
1954; Wallace and Hobbs 2006). Generally speaking, cold fronts progress toward the low latitudes whereas warm fronts progress toward the high latitudes (Shapiro and Keyser 1990). Cold fronts are steep and associated with cumulus clouds and heavy precipitation; warm fronts have a gentle slope with stratus clouds and light rain (e.g., Trewartha 1954; Wallace and Hobbs 2006). The lifetime of a typical cyclone is between 3 and 10 days. Cold fronts can be twice as fast as warm fronts (e.g., Trewartha 1954; Wallace and Hobbs 2006); a midlatitude low-pressure cyclone system usually decays when the cold front "catches up" with the warm front (known as an occlusion front).

The features of the cold/warm fronts seem to be associated with the observed temperature asymmetry in the following ways: (i) The midlatitude synoptic cyclone cold or warm front activity transports heat from the low latitudes to the high latitudes (the asymmetry map shown in Fig. 2 resembles the map of transient heat transport shown in Fig. 6; see more details below). (ii) A low-pressure system moving to the east and located at latitudes higher than the observer will, in some cases, first cause a gradual warming due to the presence of the warm front followed by a more rapid cooling due to the passing of the cold front. This will lead to a temperature midlatitude asymmetry as in Fig. 2. (We note however, that a warm front does not necessarily have to precede a cold front to obtain an average asymmetry that is larger than 0.5 -even temporally separated cold or warm events may lead in principle to asymmetry larger than 0.5.) (iii) In times and locations where only cold or warm fronts are active, the radiative relaxation to "normal" atmospheric conditions will be 


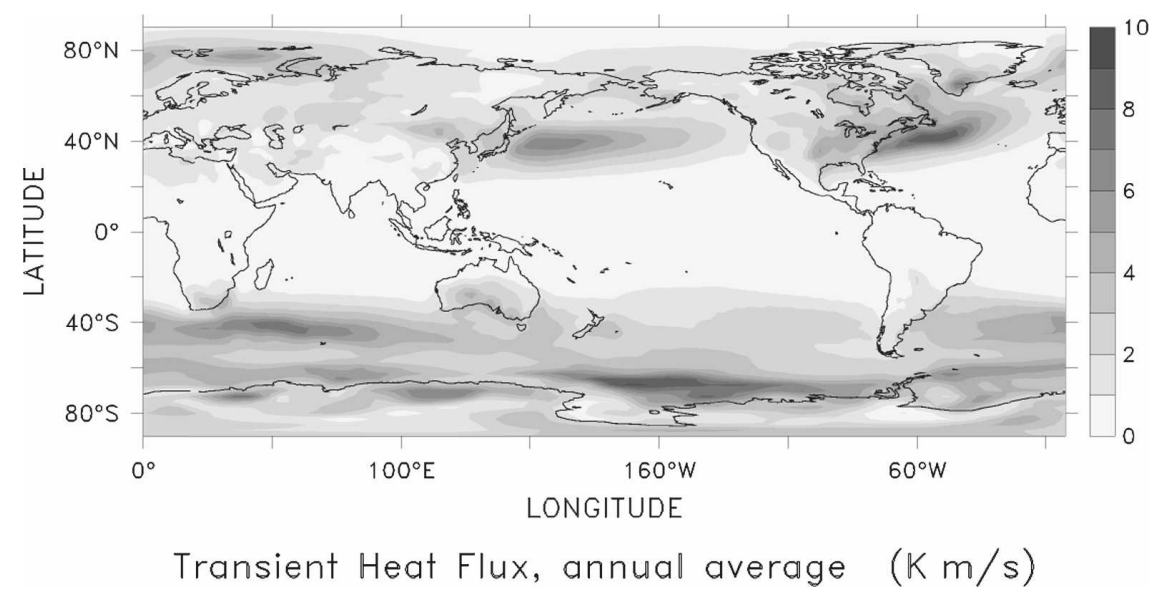

FIG. 6. The annual average of the transient heat flux $\sqrt{\overline{u^{\prime} T^{\prime}} 2+{\overline{v^{\prime} T^{\prime}}}^{2}}\left(\mathrm{~K} \mathrm{~m} \mathrm{~s}^{-1}\right)$.

gradual; as mentioned above, warm fronts tend to progress poleward whereas cold fronts tend to progress equatorward, possibly resulting in rapid warming (cooling) of the high (low) latitudes. (iv) The passing of the warm and cold fronts and the relaxation to normal atmospheric conditions take a few days, consistent with the decay of the temperature asymmetry when considering a time lag of more than $\tau=4$ days (Fig. 3b). (v) Because well-developed frontal zones are limited to heights lower than the 500 -hPa level, and because the cold front slope becomes much more moderate with height (Trewartha 1954; Wallace and Hobbs 2006), one would expect the asymmetry to decay above this height, as indeed demonstrated in Fig. 4.

\section{Transient heat flux and daily temperature asymmetry}

The transient heat flux ${ }^{1}$ shown in Fig. 6 is based on the surface, daily average, zonal and meridional wind fields $u$ and $v$ and on the daily average surface temperature field $T$; it is similar to the maps shown in Gill (1982) and in Lau and Wallace (1979). We assume that $u=\bar{u}+u^{\prime}, v=\bar{v}+v^{\prime}$, and $T=\bar{T}+T^{\prime}$, where the overbars indicate a 5 -day running mean and the primes indicate the deviations from the running mean. We choose a 5-day running mean following Fig. $3 \mathrm{~b}$ in which the asymmetry almost entirely decays for lags above 4 days. The zonal and meridional transient heat flux are then $\overline{u^{\prime} T^{\prime}}$ and $\overline{v^{\prime} T^{\prime}}$, and hence the magnitude of the transient heat flux vector is given by $\sqrt{\overline{u^{\prime} T^{\prime}}{ }^{2}+{\overline{v^{\prime} T^{\prime}}}^{2}}$.

\footnotetext{
${ }^{1}$ It is necessary to multiply the heat flux values by $\rho C_{v}$ to obtain "real" heat flux units.
}

Generally speaking, there is a good correspondence between the transient heat flux shown in Fig. 6 and the asymmetry results shown in Fig. 2, strengthening in some sense the association of the asymmetry with eddy activity. In regions of large transient heat flux, the asymmetry is also prominent, possibly due to more cyclones (with cold and warm fronts) that are observed there. However, the differences between Figs. 2 and 6 can be attributed to the fact that the velocity of the cold front relative to that of the warm front may change from place to place; this may drastically affect the asymmetry in daily temperature records, but not the transient heat flux. Moreover, direct heat advection through the lower branches of the Hadley, Ferrel, and polar cells may also contribute to the transient heat transport, but not to the asymmetry.

To further demonstrate the link between the asymmetry and the transient heat flux, we briefly consider the Sahara region. The asymmetry over the Sahara desert region (between $20^{\circ}-40^{\circ} \mathrm{N}$ and $0^{\circ}-30^{\circ} \mathrm{E}$ ) is large, although one may expect a weak cyclonic activity in such a desert area. We show in Fig. 7 further detailed results of the transient heat flux and the asymmetry index $A$. In the Sahara desert there are cyclones, the "Saharan lows", that are usually associated with the so-called "Hamsin" (Sharav) winds; these are dry and hot westerly winds blowing over the Sahara. These synoptic systems are formed in the lee of the Atlas Mountains and are characterized by a significant sharp cold front and a much weaker warm front (Alpert and Ziv 1989). The Hamsin winds are most active during March-May (Goldreich 2003). This is also clear from the transient heat flux (Fig. 7a), which peaks in April. The average temperature asymmetry in this region (Fig. 7b) shows a similar pattern, apparently with 

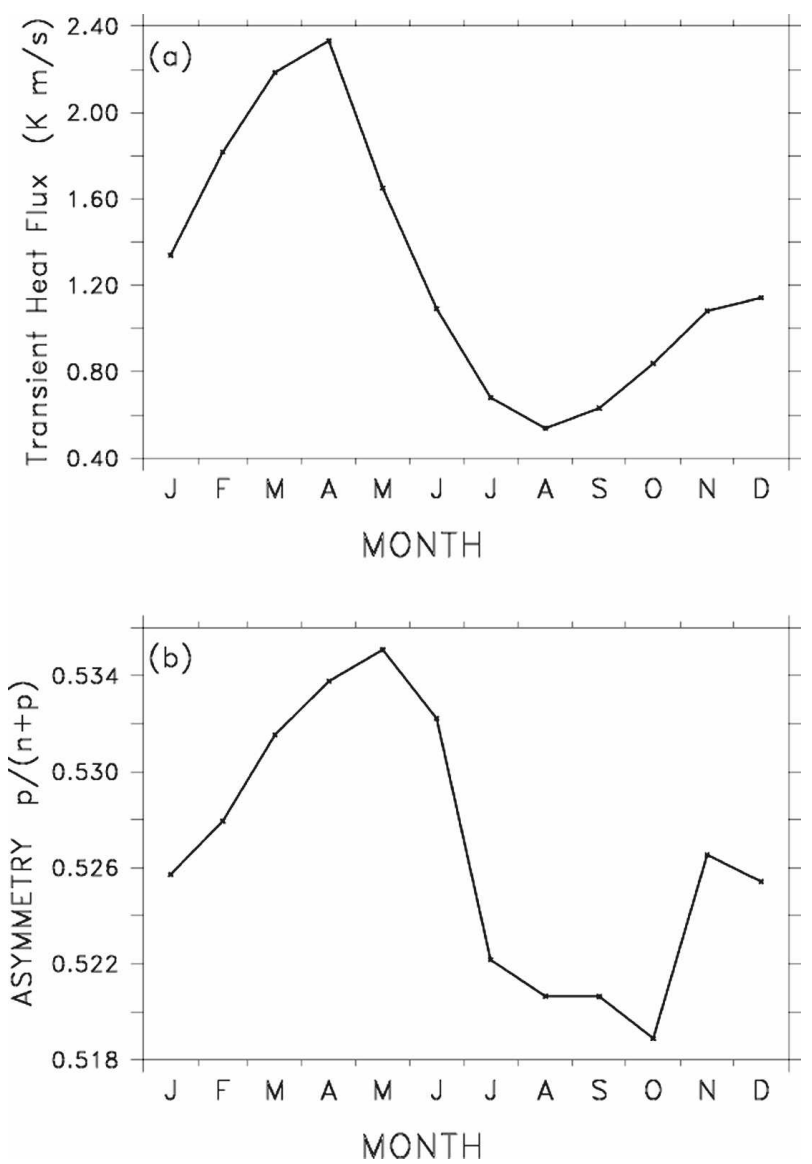

FIG. 7. (a) The transient heat flux $\left(\mathrm{K} \mathrm{m} \mathrm{s}^{-1}\right)$ for the different months averaged over the eastern part of North Africa $\left(20^{\circ}-40^{\circ} \mathrm{N}\right.$, $\left.0^{\circ}-30^{\circ} \mathrm{E}\right)$. (b) Same as (a), but for the asymmetry measure.

1-month lag. This similarity of the asymmetry and the eddy heat flux patterns for the Hamsin phenomenon further strengthens our suggestion that the asymmetry in the daily average temperature is associated with the cold or warm front dynamics.

Figure 8 depicts a case study for which a cold front resulted in rapid cooling and gradual warming. During 2-3 April 2006 a strong storm occurred in the northeastern part of North America (see http://nws.met.psu. edu/severe/2006/03Apr2006.pdf). The cold air originated at higher latitudes and moved eastward. The drop in daily averaged temperature was more than $6^{\circ} \mathrm{C}$ from 1 to 2 April 2006 at $55^{\circ} \mathrm{N}, 65^{\circ} \mathrm{W}$; then the temperature increased for three consecutive days (Fig. 8d). Thus, the asymmetry of the temperature record during this event is relatively large. In addition, the cold southward intrusion seen at the left of Fig. $8 \mathrm{c}$ progressed to the east, and caused another, more moderate, event of rapid cooling and more gradual warming.

In spite of the above arguments that suggest a link between the asymmetry of daily temperatures and mid- latitude synoptic-scale activity, we find that the location of the seasonal storm track does not coincide with the location of the high-asymmetry features; we observed similar dissimilarity between seasonal transient heat flux and the seasonality in the asymmetry. In Fig. 9 we present the annual mean of the number of cyclones per month, per grid point as a measure of the storm track. Following Lambert (1988) and Bell and Bosart (1989) we define a pressure low (cyclone) as a grid point that is lower than its four neighbors at least by $\Delta P$ (here we choose $\Delta P=2 \mathrm{hPa}$ ). When using a smaller $\Delta P$ we obtain a similar pattern although covering a larger latitude band. The annual pattern presented in Fig. 9 is similar to the overall pattern of the asymmetry measure presented in Fig. 2. However, the seasonal variability of the cyclone statistics (Fig. 10) is different from that of the asymmetry presented in Fig. 5. There are more frequent cyclone events during the wintertime (Fig. 10), when the Hadley cell is more active, whereas the asymmetry $(A>0.5)$ is stronger during the summer. This difference indicates that the asymmetry may not necessarily be associated only with cold or warm fronts associated with cyclones in the storm track.

It might be, however, that most cyclones are symmetric (i.e., the structure and speed of the fronts result in similar cooling or warming rates) and that they are more asymmetric during summer, thus explaining the difference between the asymmetry of daily temperatures and the storm track pattern. We conclude that the physical mechanism of the asymmetry may partially be due to passing fronts, but may also include additional physical processes that we were not able to identify.

\section{Summary}

We report here the asymmetry of daily temperature records, showing that temperature cools rapidly and warms gradually at the midlatitudes. At higher latitudes we observe an opposite asymmetry with rapid warming and gradual cooling, whereas at the low latitudes there is no significant asymmetry.

There are several indications for the link between the observed asymmetry and synoptic-scale activity: (i) The annual mean storm track and the transient heat patterns resemble the annual mean asymmetry pattern, (ii) the typical lifetime of a cyclone (roughly 1 week) may explain why we find insignificant asymmetry for time lags larger than 5 days, and (iii) the asymmetry is very weak at $500 \mathrm{hPa}$, similar to the weak frontal cyclone activity at this height.

There are several partially related ways according to which synoptic-scale activity may affect the asymmetry. 
(a) 02-APR-2006 12:00

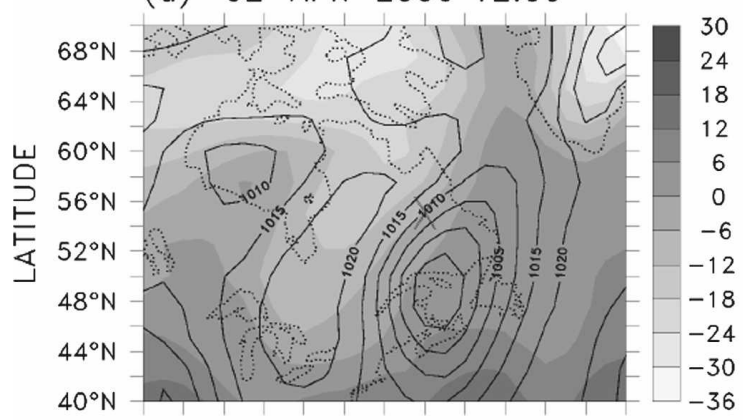

$100^{\circ} \mathrm{W} 90^{\circ} \mathrm{W} 80^{\circ} \mathrm{W} 70^{\circ} \mathrm{W} 60^{\circ} \mathrm{W} 50^{\circ} \mathrm{W} 40^{\circ} \mathrm{W}$ LONGITUDE

Surface air temprature $\left({ }^{\circ} \mathrm{C}\right)$

(c) 04-APR-2006 12:00

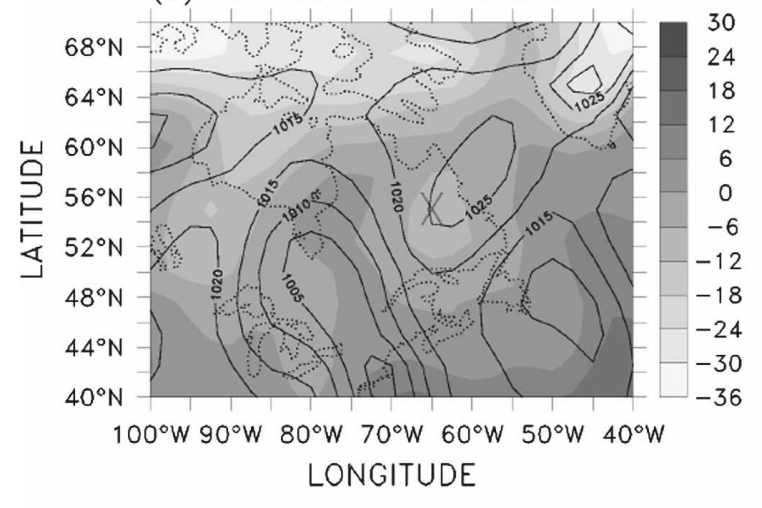

Surface air temprature $\left({ }^{\circ} \mathrm{C}\right)$ (b) 03-APR-2006 12:00

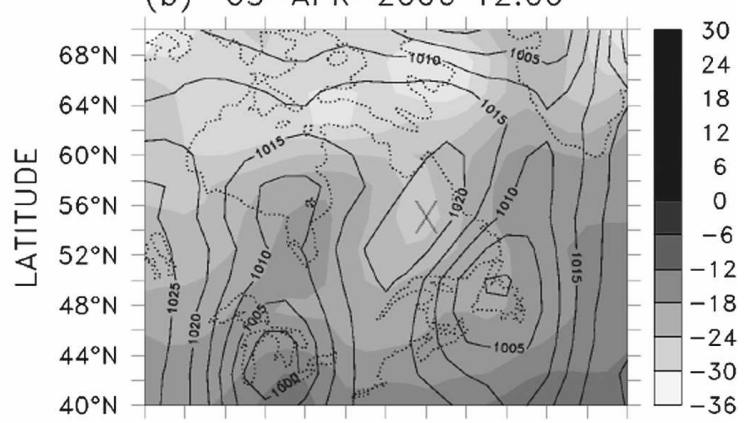

$100^{\circ} \mathrm{W} 90^{\circ} \mathrm{W} 80^{\circ} \mathrm{W} 70^{\circ} \mathrm{W} 60^{\circ} \mathrm{W} 50^{\circ} \mathrm{W} 40^{\circ} \mathrm{W}$ LONGITUDE

Surface air temprature $\left({ }^{\circ} \mathrm{C}\right)$

(d)

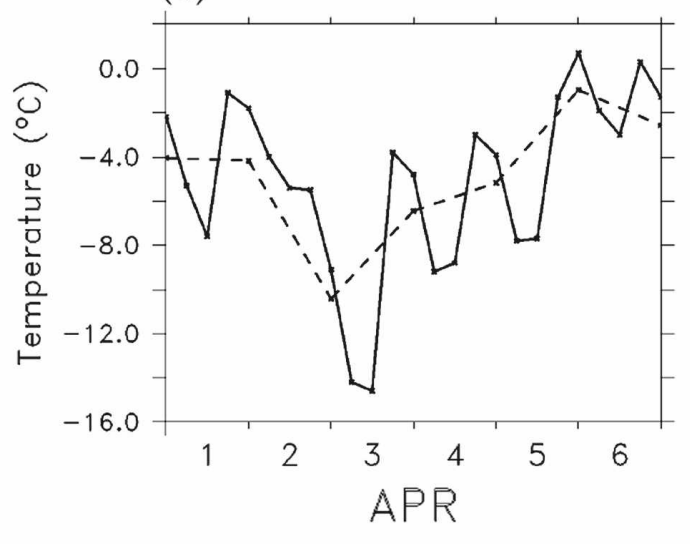

FIG. 8. (a)-(c) Surface temperature (gray shading) and mean sea level pressure (black contours) over northeastern North America on 1200 UTC (a) 2 Apr, (b) 3 Apr, and (c) 4 Apr 2006. The coastline is marked by the dotted contour. (d) Six-hourly (solid line) and daily mean (dashed line) temperature at $55^{\circ} \mathrm{N}, 65^{\circ} \mathrm{W}$ [indicated by an $\mathrm{X}$ in (a)-(c)] during 1-6 Apr 2006. This figure illustrates the asymmetry in surface daily temperatures caused by the passage of a cold front.

First, midlatitude cyclones are often associated with cold and warm fronts. Cold fronts are steeper and faster than warm fronts, leading to faster and stronger cooling. Thus, the asymmetry in the cold or warm fronts may be linked to the observed asymmetry in daily mean temperatures.

Second, the rapid cooling seen in the midlatitudes and the rapid warming seen in the high latitudes may be associated with the cold or warm fronts that propagate toward low/high latitudes, correspondingly. After the passage of the cold or warm front, the temperature relaxes to the equilibrium atmospheric temperature, where the (possibly radiative) relaxation process is relatively slow compared to the front propagation. At the midlatitudes, the temperature slowly relaxes after the passage of the cold front to the warmer equilibrium temperature; at the high latitudes, the temperature slowly relaxes after the passage of the warm front to the colder equilibrium temperature. During summer the equilibrium temperature at the high latitudes increases even more than the temperature caused by the warm front and thus may partially explain the change in the asymmetry during summer observed at the high latitudes of the NH (see Fig. 5).

Third, it is possible that the rapid cooling (warming) of the mid (high) latitudes is caused by intrusions of cold (warm) air from the high (low) latitudes; these intrusion events do not necessarily have the typical characteristics of the cold or warm fronts and may be associated with planetary waves.

In spite of the several indications of a link between the asymmetry in daily-averaged temperatures on the one hand and the synoptic midlatitude activity on the other, we find that other processes may also contribute to the asymmetry signal. This is indicated by the different seasonal signal in the storm track and asymmetry 


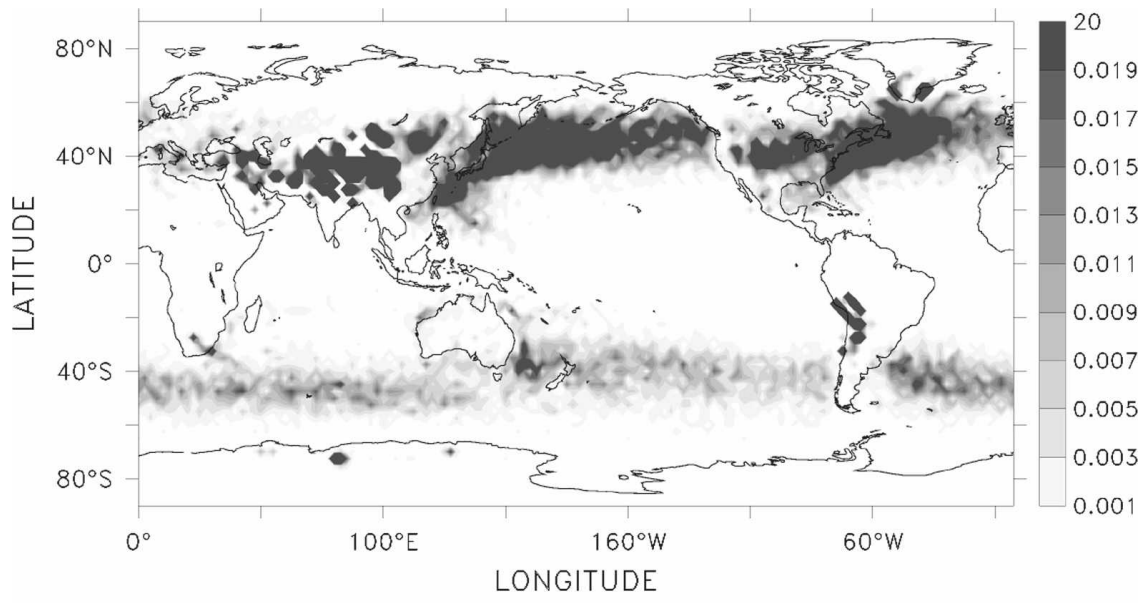

Mean number of min. SLP events per month

FIG. 9. Annual mean of the number of low-pressure events per month. A low-pressure event is defined as an event for which the pressure is lower than its four neighbors by $2 \mathrm{hPa}$.

patterns. In particular, although the midlatitude storm track is weaker during summer, the asymmetry one expects to be associated with rapid cooling associated with cold fronts $(A>0.5)$ does not weaken then. Still, it is also possible that the structure and speed of the fronts in most cyclones lead to similar cooling or warming rates and thus cannot be compared directly with the pattern of the daily temperature asymmetry. It is also plausible that other physical processes may be responsible for the observed asymmetry.

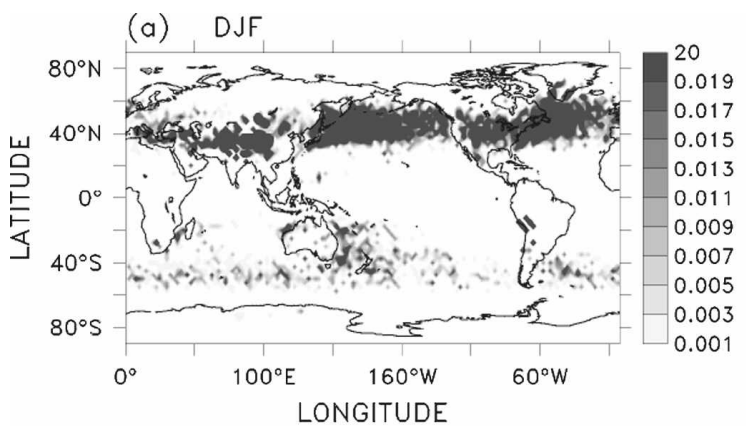

No. of min. SLP events per month

\section{(c) JJA}

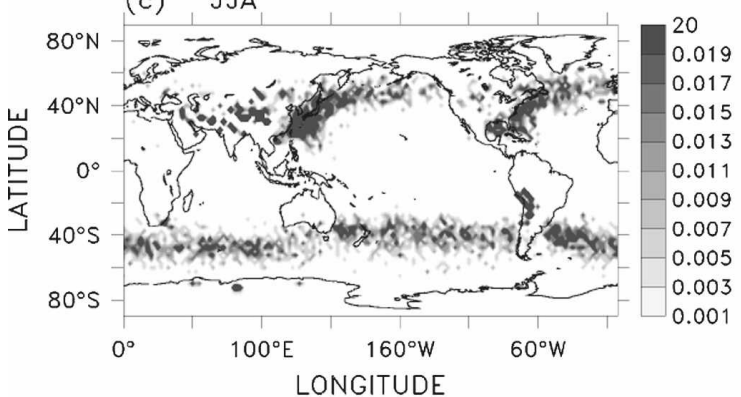

No. of min. SLP events per month

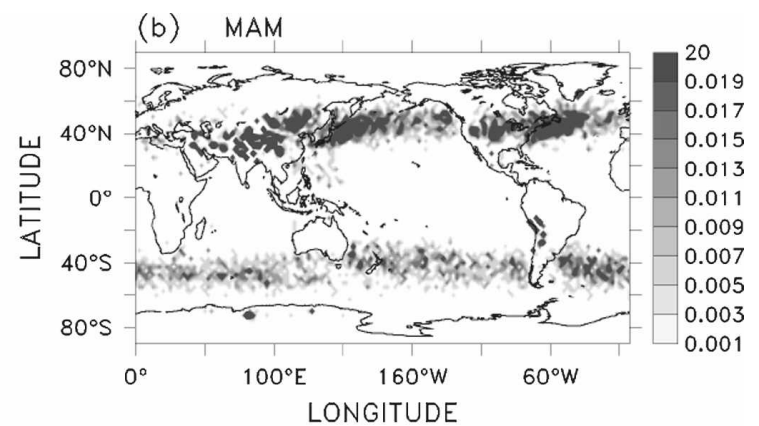

No. of min. SLP events per month

\section{(d) SON}

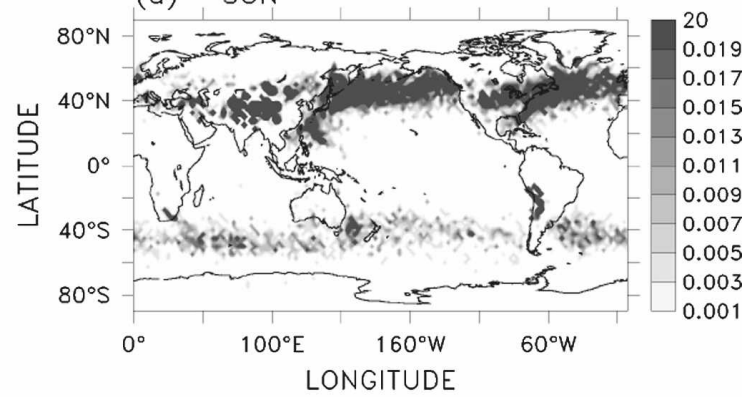

No. of min. SLP events per month

FIG. 10. As in Fig. 9, but for (a) December-February, (b) March-May, (c) June-August, and (d) September-November. The storm track is more active during winter and weaker during summer. 
Acknowledgments. We thank Brian Farrell, Yochanan Kushnir, Elad Shilo, and Baruch Ziv for helpful discussions. This research was supported by the $\mathrm{Bi}$ National Israel-U.S. Science Foundation. ET is supported by the NSF paleoclimate program Grant ATM0455470 and by the McDonnell Foundation. HG is the Incumbent of the Rowland and Sylvia Schaefer Career Development Chair.

\section{REFERENCES}

Alpert, P., and B. Ziv, 1989: The Sharav cyclone-Observations and some theoretical considerations. J. Geophys. Res., 94, 18 495-18 514.

Ashkenazy, Y., and E. Tziperman, 2004: Are the $41 \mathrm{kyr}$ glacial oscillations a linear response to Milankovitch forcing? Quat. Sci. Rev., 23, 1879-1890.

Bartos, I., and I. M. Jánosi, 2005: Atmospheric response function over land: Strong asymmetries in daily temperature fluctuations. Geophys. Res. Lett., 32, L23820, doi:10.1029/ 2005 GL024559.

—, and — 2006: Nonlinear correlations of daily temperature records over land. Nonlinear Processes Geophys., 13, 571-576.

Bell, G. D., and L.F. Bosart, 1989: A 15-year climatology of Northern Hemisphere 500-mb closed cyclone and anticyclone centers. Mon. Wea. Rev., 117, 2142-2163.

Dansgaard, W., S. J. Johnsen, H. B. Clausen, D. Dahl-Jensen, N. Gundestrup, C. U. Hammer, and H. Oescger, 1984: North Atlantic climate oscillations revealed by deep Greenland ice cores. Climate Processes and Climate Sensitivity, Geophys. Monogr., Vol. 5, Amer. Geophys. Union, 288-298.

DelSol, T., and B. F. Farrell, 1995: A stochastically excited linear system as a model for quasigeostrophic turbulence: Analytic results for one- and two-layer fluids. J. Atmos. Sci., 52, 25312547.

Farrell, B. F., 1988: Optimal excitation of neutral Rossby waves. $J$. Atmos. Sci., 45, 163-172.

— Autonomous operators. J. Atmos. Sci., 53, 2025-2040.

Gill, A. E., 1982: Atmosphere-Ocean Dynamics. Academic Press, 662 pp.

Goldreich, Y., 2003: The Climate of Israel: Observation, Research, and Application. Kluwer Academic, 270 pp.

Gyüre, B., I. Bartos, and I. M. Jánosi, 2007: Nonlinear statistics of daily temperature fluctuations reproduced in a laboratory experiment. Phys. Rev. E, 76, 037301, doi:10.1103/ PhysRevE.76.037301.

Heinrich, H., 1988: Origin and consequences of cyclic ice rafting in the Northeast Atlantic Ocean during the past 130,000 years. Quat. Res., 29, 142-152.

Holton, J. R., 1992: An Introduction to Dynamic Meteorology. 3rd ed. Academic Press, 511 pp.

Hoyt, D. V., and K. H. Schatten, 1998a: Group sunspot numbers: A new solar activity reconstruction. Part 1. Solar Phys., 179, 189-219.

$\longrightarrow$, and $\longrightarrow$, 1998b: Group sunspot numbers: A new solar activity reconstruction. Part 2. Solar Phys., 181, 491-512.

Imbrie, J., and Coauthors, 1984: The orbital theory of Pleistocene climate: Support from a revised chronology of the marine $\delta^{18} \mathrm{O}$ record. Milankovitch and Climate: Understanding the
Response to Astronomical Forcing, A. Berger et al., Eds., D. Reidel, 269-305.

Kalnay, E., and Coauthors, 1996: The NCEP/NCAR 40-Year Reanalysis Project. Bull. Amer. Meteor. Soc., 77, 437-471.

Kaspi, Y., 2002: A mechanism for the abrupt warming and simultaneous ice sheet discharge involved in Heinrich events. Master's thesis, Department of Environmental Sciences, Weizmann Institute, $53 \mathrm{pp}$.

_, R. Sayag, and E. Tziperman, 2004: A "triple sea-ice state" mechanism for the abrupt warming and synchronous ice sheet collapses during Heinrich events. Paleoceanography, 19, PA3004, doi:10.1029/2004PA001009.

Lambert, S. J., 1988: A cyclone climatology of the Canadian Climate Centre general circulation model. J. Climate, 1, 109115.

Lau, N.-C., and J. M. Wallace, 1979: On the distribution of horizontal transports by transient eddies in the Northern Hemisphere wintertime circulation. J. Atmos. Sci., 36, 1844-1861.

Lenderink, G., and R. J. Haarsma, 1994: Variability and multiple equilibria of the thermohaline circulation associated with deep-water formation. J. Phys. Oceanogr., 24, 1480-1493.

Lindzen, R., 1993: Baroclinic neutrality and the tropopause. $J$. Atmos. Sci., 50, 1148-1151.

Lisiecki, L. E., and M. E. Raymo, 2005: A Pliocene-Pleistocene stack of 57 globally distributed benthic delta O-18 records. Paleoceanography, 20, PA1003, doi:10.1029/2004PA001071.

Livina, V., Y. Ashkenazy, Z. Kizner, V. Strygin, A. Bunde, and S. Havlin, 2003: A stochastic model of river discharge fluctuations. Physica A, 330, 283-290.

Rahmstorf, S., and A. Ganopolski, 1999: Simple theoretical model may explain apparent climate instability. J. Climate, 12, 13491352.

Schreiber, T., and A. Schmitz, 1996: Improved surrogate data for nonlinearity tests. Phys. Rev. Lett., 77, 635-638.

- and - 2000: Surrogate time series. Physica D, 142, 346382.

Shapiro, M. A., and D. Keyser, 1990: Fronts, jet streams, and the tropopause. Extratropical Cyclones: The Erik Palmen Memorial Volume, C. W. Newton and E. Holopainen, Eds., Amer. Meteor. Soc., 167-191.

Trewartha, G. L., 1954: An Introduction to Climate. 3rd ed. McGraw-Hill, 402 pp.

Vallis, G. K., 2000: Large-scale circulation and production of stratification: Effects of wind, geometry, and diffusion. $J$. Phys. Oceanogr., 30, 933-954.

Wallace, J. M., and P. V. Hobbs, 2006: Atmospheric Science: An Introductory Survey. 2nd ed. Academic Press, $483 \mathrm{pp}$.

Wang, Z., and L. Mysak, 2006: Glacial abrupt climate changes and Dansgaard-Oeschger oscillations in a coupled climate model. Paleoceanography, 21, PA2001, doi:10.1029/2005PA001238.

Whitaker, J. S., and P. D. Sardeshmukh, 1998: A linear theory of extratropical synoptic eddy statistics. J. Atmos. Sci., 55, 237258.

Winton, M., 1993: Deep decoupling oscillations of the oceanic thermohaline circulation. Ice in the Climate System, W. R. Peltier, Ed., Springer-Verlag, 417-432.

_ , and E. S. Sarachik, 1993: Thermohaline oscillations induced by strong steady salinity forcing of ocean general circulation models. J. Phys. Oceanogr., 23, 1389-1410.

Zhang, Y., and I. M. Held, 1999: A linear stochastic model of a GCM's midlatitude storm tracks. J. Atmos. Sci., 56, 34163435 . 